\title{
Uses of Carbamazepine for Psychiatric Disorders: A Review
}

\author{
Edward Kim, MD \\ Jefferson Medical College, Philadelphia PA
}

Follow this and additional works at: https://jdc.jefferson.edu/jeffjpsychiatry

Part of the Psychiatry Commons

Let us know how access to this document benefits you

\section{Recommended Citation}

Kim, MD, Edward (1988) "Uses of Carbamazepine for Psychiatric Disorders: A Review," Jefferson Journal of Psychiatry. Vol. 6 : Iss. 2 , Article 10.

DOI: https://doi.org/10.29046/JJP.006.2.008

Available at: https://jdc.jefferson.edu/jeffjpsychiatry/vol6/iss2/10

This Article is brought to you for free and open access by the Jefferson Digital Commons. The Jefferson Digital Commons is a service of Thomas Jefferson University's Center for Teaching and Learning (CTL). The Commons is a showcase for Jefferson books and journals, peer-reviewed scholarly publications, unique historical collections from the University archives, and teaching tools. The Jefferson Digital Commons allows researchers and interested readers anywhere in the world to learn about and keep up to date with Jefferson scholarship. This article has been accepted for inclusion in Jefferson Journal of Psychiatry by an authorized administrator of the Jefferson Digital Commons. For more information, please contact: JeffersonDigitalCommons@jefferson.edu. 


\title{
Uses of Carbamazepine for Psychiatric Disorders: A Review
}

\author{
Edward Kim, M.D.
}

\section{INTRODUCTION}

Carbamazepine, first synthesized in 1953, was initially marketed in Europe as an anticonvulsant. In 1971 Dalby reported the drug's psychotropic effects, most notably mood stabilization, in patients with temporal lobe epilepsy (TLE) (1). Other psychiatric applications such as the treatment of affectively and behaviorally labile patients are being explored. These studies are yielding data relevant to the treatment and understanding of the neurobiology of mental illness. For this reason, familiarity with carbamazepine is becoming increasingly important to psychiatrists.

\section{CHEMISTRY AND PHARMACOLOGY}

Carbamazepine is structurally similar to the tricyclic antidepressant imipramine (Fig. 1) (2,3). Plasma levels peak four to eight hours after ingestion, with $75 \%$ of the drug bound to plasma proteins. CSF levels are dependent on the level of unbound drug in plasma. Metabolism occurs primarily in the liver via the cytochrome P-450 oxidase system, producing carbamazepine-10,11-epoxide which is as active and may reach levels up to half that of carbamazepine. This is almost entirely converted to carbamazepine-trans-10,11-dihydrodiol by epoxide hydrolase before excretion in the urine (Fig 2) (4). The epoxide is $50 \%$ protein-bound in plasma (5).

Carbamazepine induces hepatic enzymes, thus enhancing its own metabolism. Therefore, the 30-hour half-life of a single oral dose drops to 20 hours at three weeks at 12 hours after several months. The half-life is reduced in patients who simultaneously take other inducers of hepatic enzymes such as phenobarbital, phenytoin, or alcohol (4). Carbamazepine also enhances the metabolism of phenytoin and warfarin for the same reason (6).

\section{CLINICAL GUIDELINES}

The most common side effect is an allergic skin rash which occurs in $5 \%$ to $15 \%$ of treated patients (7). This may be accompanied by sore throat, mucosal ulceration and low grade fever. Antihistamines can be effective in eliminating 


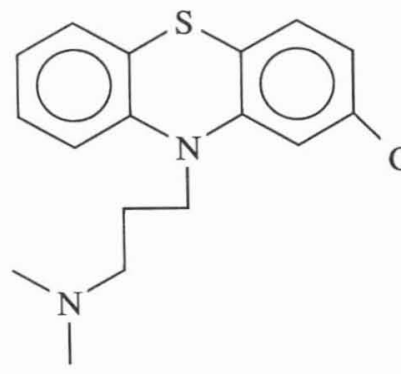

Chlorpromazine

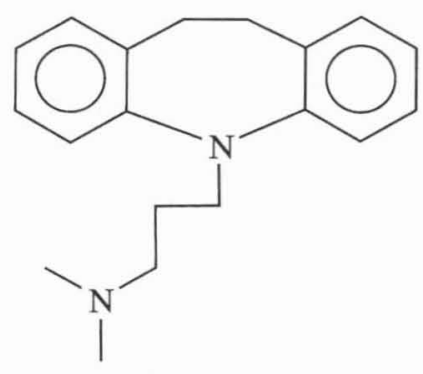

Imipramine

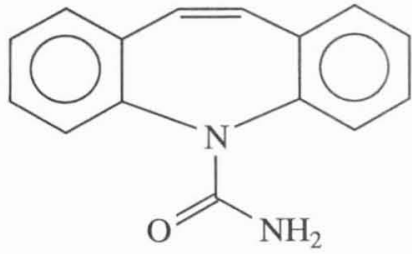

Carbamazepine

FIGURE 1. The tricyclic structure of carbamazepine resembles that of imipramine and, to a lesser extent, chlorpromazine. Carbamazepine blocks norepinephrine reuptake but does not block dopamine receptors

allergic symptoms, though the rash may require discontinuation of carbamazepine. Carbamazepine-induced agranulocytosis has received much attention because of its mortality rate of up to $50 \%$. However, less than thirty cases have been reported (2). This idiosyncratic reaction has a prevalence of one in 20,000 to 40,000 and is unrelated to a harmless $25 \%$ decrease in white cell count which is fairly common (7). About $10 \%$ of patients receiving the drug develop a mild dose-related leukopenia which resolves within the first four months. Of these, approximately $2 \%$ continue with a persistent leukopenia which necessitates discontinuation of therapy (2). Neurotoxic side effects of carbamazepine may include drowsiness, vertio, ataxia, diplopia, and blurred vision. Patients acutely intoxicated on the drug can exhibit sedation, respiratory depression, hyperirritability, and even seizures. Other side effects include nausea and vomiting, and hepatotoxicity ranging from mild elevation of serum transaminases to acute hepatitis. In addition, chronic administration can also cause a condition resembling the syndrome of inappropriate secretion of antidiuretic hormone (SIADH), with water retention, hyponatremia, and possible water intoxication (2).

The initial dose of carbamazepine in healthy adults is $200 \mathrm{mg}$ once or twice a day. This is increased by no more than $200 \mathrm{mg}$ a day to a total of $200 \mathrm{mg}$ t.i.d. A serum level should be checked after five days and dosage adjusted accordingly (7). The actuity of the patient dictates how aggressively the dosage should be increased, but the appearance of neurotoxicity is a clear indication for smaller, more gradual increments. Maintenance doses average about $1000 \mathrm{mg} /$ day, though the range may vary from 200 to $1600 \mathrm{mg}$ /day (8). In patients who are elderly or have liver disease, dosage and increments should be appropriately decreased. Therapeutic serum levels range from $6-12 \mu \mathrm{g} / \mathrm{ml}$; neurotoxic side effects are more frequent above $10 \mu \mathrm{g} / \mathrm{ml}(2,4)$. Levels should be checked frequently during initial therapy since $90 \%$ of enzyme induction occurs in the 


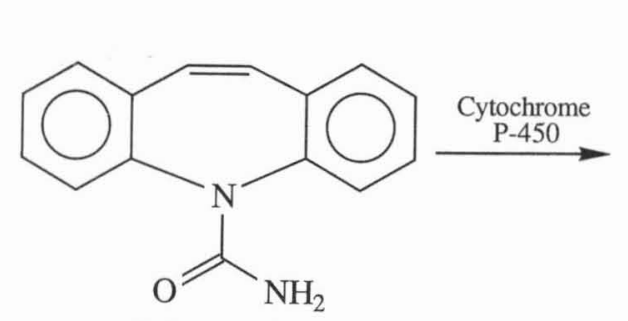

Carbamazepine (CBZ)

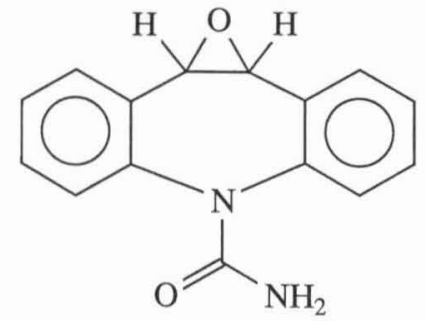

CBZ-10,11-epoxide

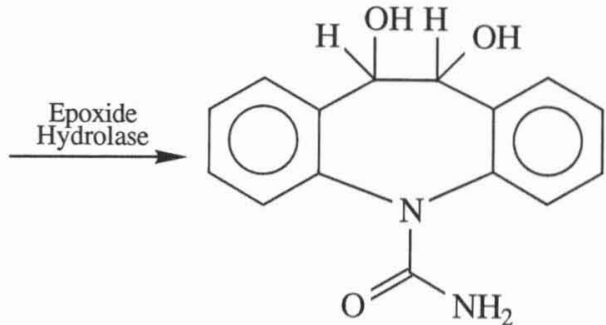

CBZ-trans-10,11-dihydrodiol

FIGURE 2. Metabolic pathway of carbamazepine. Both the epoxide and dihydrodiol are excreted in the urine. 
first month (7). Moreover, a complete blood count and liver panel should be checked prior to and periodically during treatment (2).

\section{NEUROLOGIC AND ENDOCRINE APPLICATIONS}

Carbamazepine, a potent anticonvulsant is the drug of choice in temporal lobe epilepsy (9), and a first-line drug in controlling grand mal seizures. It is also effective in the treatment of trigeminal neuralgia and other chronic pain syndromes (10-13). Its antidiuretic properties have led to its use in managing diabetes insipidus (10).

\section{APPLICATIONS IN MOOD DISORDERS}

Most psychiatric trials of carbamazepine have been conducted with patients with bipolar disorder, although some studies have included schizoaffective patients in their test groups. Beginning in the early 1970's Okuma et al $(15,16)$ in Japan demonstrated that carbamazepine is beneficial in the treatment of acutely manic patients and in longterm prophylaxis against mania. In a doubleblind controlled study, Post et al (17) at the National Institutes of Mental Health reported carbamazepine's clear efficacy over placebo in symptom relief in seven out of nine (88\%) manic patients. Of these, four (57\%) relapsed during placebo administration.

The drug's acute anti-manic efficacy is approximately that of chlorpromazine (18). In over half of treated patients, peak antimanic effects were reached within ten days of administration of either chlorpromazine or carbamazepine. Carbamazepine also lowered scores on the Clinical Global Impression (CGI) scale on average as much as lithium (19). Lithium, however, had a more consistent anti-manic effect than carbamazepine: the changes in CGI scores tended to cluster around the mean in patients treated with lithium, while the mean CGI change in carbamazepine-treated patients was largely due to a few who responded extremely well. A double-blind 3-year study comparing lithium $(n=27)$ and carbamazepine $(n=29)$ found both drugs effective in about two thirds of treated patients (26). Peak symptom relief was reached within three months of treatment onset in both groups. The only striking difference between the drugs was their relative dropout rates. Lithium-treated patients with more schizophrenic or schizoaffective symptoms had a significantly higher dropout rate than carbamazepine-treated patients (50\% vs. $20 \%$, respectively). In contrast, patients who demonstrated "classical" bipolar psychotic features had a lower dropout rate when treated with lithium (20\% vs. $35 \%$, respectively).

Investigators are attempting to define a population of patients who are particularly responsive to carbamazepine and who, therefore, would be considered prime candidates for this treatment early in their illness. Some patients with a history of lithium resistance responded better when carbamazepine was added to or substituted for lithium $(17,21)$. In two open clinical trials with 
bipolar and schizoaffective patients resistant to lithium and/or neuroleptic maintenance $(22,23)$, a total of 14 out of $21(67 \%)$ of those patients improved when carbamazepine was added or substituted into their treatment regimen. Observations that rapid-cycling bipolar patients respond well to carbamazepine $(17,21,22,24)$ have yet to be demonstrated in controlled clinical trials.

The drug's therapeutic effect in depressed patients is somewhat less clear, with five of thirteen (38\%) bipolar patients showing marked improvement in Post et al's original report (17), and twelve of thirty-five (34\%) showing marked improvement in a subsequent study which involved bipolar $(n=24)$ and unipolar $(n=11)$ depressed patients (25). The antidepressant effect is related to plasma levels of the epoxide metabolite rather than carbamazepine itself (26). The drug's time course of action in depression is similar to that of tricyclic antidepressants (TCA's), with substantial improvements occurring after two weeks and maximum effect after three weeks (27). Because TCA's are known to induce more rapid cycling in some bipolar patients treated for depression (28), carbamazepine may be considered as an alternative treatment in patients with a history of rapid cycling or mania during TCA therapy. One depressed bipolar patient with a history of TCA-induced mania despite lithium prophylaxis responded well to carbamazepine without cycling into mania (29). A recent case report described the successful treatment of a bipolar depressed patient using carbamazepine and electroconvulsive therapy (30).

\section{OTHER PSYCHIATRIC APPLICATIONS}

Carbamazepine was found to markedly decrease the severity and frequency of behavioral dyscontrol in some women with borderline personality disorder (30). The patients often reported an enhanced ability to think before acting, a phenomenon referred to as "reflective delay." This resulted in fewer angry outbursts, episodes of violence, and suicide threats or attempts during the trial period. In contrast, the placebo group showed no such improvements, and seven of eleven placebo patients $(64 \%)$ were removed from the trial early because of behavioral deterioration, compared with one of fourteen of the carbamazepine trials (7\%). In addition, the drug has also proven helpful in the treatment of patients with mixed frontal lobe disease and schizophrenia or schizoaffective disorder with affective or behavioral liability (31).

Carbamazepine is more effective than placebo when used in conjunction with haloperidol in the treatment of excited psychoses of schizophrenic and schizoaffective, as well as manic, patients (32). Because of this apparent efficacy in patients exhibiting more schizophrenic features (22), the effects of carbamazepine on the dopaminergic pathway have been studied by Post et al (33). They found that carbamazepine decreased probenecid-induced CSF accumulation of homovanillic acid (HVA), a dopamine metabolite, and had no effect on baseline CSF concentrations of HVA. This is in contrast to neuroleptics which increase both baseline and probenecid-treated HVA levels in CSF. This, in addition to 
the absence of reported cases of tardive dyskinesia, suggests that carbamazepine does not exert its effect by dopamine receptor blockade. This is consistent with previous animal studies (34). Rather, the drug may work by decreasing dopamine turnover in the brain. Thus far, carbamazepine has not proven useful in treating tardive dyskinesia (35).

\section{DRUG INTERACTIONS}

Two recent reports have demonstrated that carbamazepine can reduce plasma levels of haloperidol when the two are administered simultaneously $(36,37)$. This may be due to hepatic enzyme induction resulting in accelerated metabolism of haloperidol. Therefore, larger neuroleptic doses may be necessary for the management of patients treated concurrently with carbamazepine.

Another potential complication of carbamazepine treatment is neurotoxicity during coadministration with lithium (38). Patients may present with confusion, drowsiness, weakness, lethargy, coarse tremor, hyperreflexia, nystagmus, and cerebellar ataxia. These symptoms can be seen in both lithium (39) and carbamazepine toxicity (40). In this case, however, neurotoxicity may develop at "nontoxic" plasma levels of each drug. Therefore, monitoring of drug levels may not protect patients against developing adverse effects. Fortunately the neurotoxicity is rapidly reversible following discontinuation of treatment. A history of lithium-induced neurotoxicity is a prominent risk factor for this complication (38).

On the other hand, coadministration of carbamazepine and lithium offers a potentially beneficial interaction. Carbamazepine can induce water retention leading to hyponatremia and water intoxication $(41,42)$. Lithium, on the other hand, has been used to treat such water retention in SIADH by inducing a nephrogenic diabetes insipidus (43). These opposite effects on plasma sodium and fluid balance can offset one another so that patients receiving lithium in addition to carbamazepine may be less likely to develop hyponatremia than patients treated with carbamazepine alone (44).

The use of carbamazepine in conjunction with TCA's and monoamine oxidase inhibitors (MAOI's) has not been systematically studied. However, we can make some inferences on the basis of carbamazepine's structure and pharmacology. The drug inhibits presynaptic reuptake of norepinephrine by approximately $25 \%$, compared to $85 \%$ in the case of imipramine (3). Therefore carbamazepine should be used like other TCA's and started prior to or at the same time as MAOI's when combination therapy is desired (45). Combined TCA-MAOI treatment, while raising concerns about hypertensive crisis, has been extensively reviewed and found to be safe and efficacious when administered properly $(46,47)$.

A number of drugs inhibit the metabolism of carbamazepine and may cause increased serum levels. These include erythromycin, verapamil, diltiazem, isoniazid, nicotine, and the opiate propoxyphene (4). Through enzyme induc- 
tion carbamazepine decreases serum levels of phenytoin and warfarin as well as doxycycline, sodium valproate, ethosuximide, and clonazepam $(3,4)$.

\section{THEORETICAL CONSIDERATIONS}

The efficacy of carbamazepine in the treatment of excited psychoses raises questions about the neurobiology of psychiatric illness. In the late 1960's it was observed that dominant hemisphere TLE predisposes patients to psychosis, while nondominant hemisphere TLE is associated with bipolar illness (48). This study compared fifty TLE patients with psychotic features with fifty nonpsychotic TLE patients. The presence of psychosis was inversely correlated with seizure activity. A more recent study found that 11 of 17 (65\%) of TLE patients and zero of seven generalized epileptics had at least one of the eight Schneiderian first-rank symptoms for schizophrenia (49). Dalby's study (1) goes on to demonstrate that TLE patients treated with carbamazepine had markedly reduced affective symptoms such as anxiety, paranoia, and aggressive behavior in 24 of $58(44 \%)$ patients. Moreover, several patients improved psychiatrically despite a lack of seizure control. While nearly half of Dalby's epileptic patients had structural brain abnormalities, most subsequent studies of the psychotropic effects of carbamazepine have screened out patients with structural or electroencephalographic abnormalities.

Post et al (50) proposed a theory of agitated psychosis which involved a phenomenon called "kindling." Repetitive subthreshold stimulation of the limbic system produces a hyperexcitable "kindled" state in which motor seizures may be induced by stimulation that was previously non-seizurogenic. Reviewing the literature on the effects of chronic administration of cocaine and other CNS stimulants, they noted that subjects developed hypersensivity rather than tolerance to the effects of these substances on pathological behavior and seizures.

Carbamazepine, in addition to phenobarbital and diazepam, is very effective in blocking experimental electrically kindled amygdaloid seizures in a variety of animal species (51). Phenytoin, another potent anticonvulsant, is much less effective in blocking kindled amygdaloid seizures. Moreover, phenytoin exhibits no significant therapeutic effect on manic patients (52). This suggests the possibility of a limbic focus for the generation of mania and other excited psychoses. The mechanism may involve subthreshold kindling of limbic structures. The absence of structural and physiologic abnormalities in such patients could be more reflective of instrumental limitations than the absence of organic pathology.

\section{CONCLUSIONS}

Carbamazepine, once used only in the treatment of epilepsy and neuropathic pain, is becoming increasingly important in the treatment of some psychiat- 
ric patients, but that group is not yet clearly defined. Because of potential adverse effects and drug interactions, it should be administered judiciously in selected patients who can be carefully monitored. Nevertheless, it is becoming evident that for a certain subset of psychiatric patients, carbamazepine alone or in combination with other drugs may prove to be the only effective treatment that is currently available.

\section{REFERENCES}

1. Dalby MA: Antiepileptic and psychotropic effect of carbamazepine (Tegretol[r]) in the treatment of psychomotor epilepsy. Epilepsia 12:325-334, 1971

2. Gilman AG, Goodman LS, Rall TW, et al (eds): The Pharmacological Basis of Therapeutics. New York, MacMillan Publishing Company, pp. 457-459, 1985

3. Post RM, Ballenger JC, Uhde TW et al: Efficacy of carbamazepine in manicdepressive illness, in Post RM and Ballenger JC: Neurobiology of Mood Disorders. Baltimore, Williams and Wilkins, pp 777-816, 1984

4. Levy RH, Kerr BM: Clinical pharmacokinetics of carbamazepine. J Clin Psychiatry 49(suppl.): 58-61, 1988

5. Johannsen SI: Antiepileptic drugs: pharmacokinetics and clinical aspects. Ther Drug Monit 3: 17-37, 1974

6. Hansen JM, Siersbaek-Nielsen K, Skovsted L: Carbamazepine-induced acceleration of diphenylhydantoin and warfarin metabolism in man. Clin Pharm Ther 12:539543,1971

7. Neppe VM, Tucker GJ, Wilensky AJ: Introduction: fundamentals of carbamazepine use in neuropsychiatry. J Clin Psychiatry 49(suppl.): 4-6, 1988

8. Hyman SE, Arana GW: Handbook of Psychiatric Drug Therapy. Baltimore, Little, Brown, and Company, pp. 98-114, 1987

9. Bird CAK, Griffin BP, Miklaszewska JM, et al: Tegretol (carbamazepine): a controlled trial of a new anticonvulsant. Br J Psych 112:737-742, 1966

10. Ekbom K: Carbamazepine in the treatment of tabetic lightning pains. Arch Neurol 26:374-378, 1972

11. Elliot F, Little A, Millbrandt W: Carbamazepine for phantom-limb phenomena (letter). N Engl J Med 295:678, 1976

12. Taylor JC, Brauer S, Espir MLE: Long-term treatment of trigeminal neuralgia with carbamazepine. Postgrad Med J 57:16-18, 1981

13. Sweet WH: The treatment of trigeminal neuralgia (tic doloroureux). N Engl J Med 315:174-177, 1986

14. Wales JK: Treatment of diabetes insipidus with carbamazepine. Lancet 1:948-951, 1975

15. Okuma T, Kishimoto A, Inoue K, et al: Anti-manic and prophylactic effects of carbamazepine on manic-depressive psychosis. Folia Psych Neurol Jpn 27:283-297, 1973

16. Okuma $\mathrm{T}$, Inanaga $\mathrm{K}$, Otsuki $\mathrm{S}$, et al: A preliminary double-blind study on the efficacy of carbamazepine in prophylaxis of manic-depressive illness. Psychopharm 73:95-96, 1981

17. Ballenger JC, Post RM: Carbamazepine in manic-depressive illness: a new treatment. Am J Psych 137:782-790, 1980 
18. Okuma $\mathrm{T}$, Inanaga $\mathrm{K}$, Otsuki $\mathrm{S}$, et al: Comparison of the antimanic efficacy of carbamazepine and chlorpromazine: a double-blind controlled study. Psychopharm $66: 211-217,1979$

19. Lerer B, Moore N, Meyendorff E, et al: Carbamazepine versus lithium in mania: a double-blind study. J Clin Psych 48:89-93, 1987

20. Placidi GF, Lenzi A, Lazzerini F, et al: The comparative efficacy and safety of carbamazepine versus lithium: a randomized, double-blind 3-year trial in 83 patients. J Clin Psych 47:490-494, 1986

21. Fawcett J, Kravitz HM: The long-term management of bipolar disorders with lithium, carbamazepine, and antidepressants. J Clin Psych 46:58-60, 1985

22. Folks DG, King LD, Dowdy SB, et al: Carbamazepine treatment of selected affectively disordered inpatients. Am J Psych 139:115-117, 1982

23. Elphick M: An open clinical trial of carbamazepine in treatment-resistant bipolar and schizo-affective psychotics. Br J Psych 147:198-200, 1958

24. Roy-Byrne PP, Joffe RT, Uhde TW, et al: Approaches to the evaluation and treatment of rapid-cycling affective illness. Br J Psych 145:543-550, 1984

25. Post RM, Uhde TW, Roy-Byrne PP, et al: Antidepressant effects of carbamazepine. Am J Psych 143:29-34, 1986

26. Post RM, Uhde TW, Ballenger JC: Carbamazepine and its -10,11-epoxide metabolite in plasma and CSF-relationship to antidepressant response. Arch Gen Psych 40:673-676, 1983

27. Post RM: Time course of clinical effects of carbamazepine implications for mechanism of action. J Clin Psychiatry 49 (suppl): 35-40, 1988

28. Wehr TA, Goodwin FK: Rapid cycling in manic-depressives induced by tricyclic antidepressants. Arch Gen Psych 36:555-559, 1979

29. Nurnber HG, Finkel JA: Carbamazepine in bipolar-depressed disorder complicated by tricyclic switching: case report

30. Cantor C: Carbamazepine and ECT: a paradoxical combination (letter). J Clin Psych $47: 276-277,1986$

31. Gardner DL, Cowdry RW: Positive effects of carbamazepine on behavioral dyscontrol in borderline personality. Am J Psych 143:519-522, 1986

32. McAllister TW: Carbamazepine in mixed frontal lobe and psychiatric disorders. J Clin Psychiatry 46:393-394, 1985

33. Klein E, Bental E, Lerer B, et al: Carbamazepine and haloperidol v placebo and haloperidol in excited psychoses. Arch Gen Psych 41:165-170, 1984

34. Post RM, Rubinow DR, Uhde TW, et al: Dopaminergic effects of carbamazepine. Arch Gen Psych 43:392-396, 1986

35. Marangos PJ, Post RM, Patel J, et al: Specific and potent interactions of carbamazepine with brain adenosine receptors. Eur J Pharmacol 93:175-182, 1983

36. Yassa R: Carbamazepine in the treatment of tardive dyskinesia (letter). Am J Psych $143: 1191,1986$

37. Fast DK, Jones BD, Kusalic M, et al: Effect of carbamazepine on neuroleptic plasma levels and efficacy (letter). Am J Psych 143:117-118, 1986

38. Arana GW, Goff DC, Friedman H: Does carbamazepine-induced reduction of plasma haloperidol levels worsen psychotic symptoms? Am J Psych 143:650-651, 1986

39. Shukla S, Godwin CD, Long LEB, et al: Lithium-carbamazepine neurotoxicity and risk factors. Am J Psych 141:1604-1606, 1984 
40. Shopsin D, Johnson G, Gershon S: Neurotoxicity with lithium: differential drug responsiveness. Int Pharmacopsych 5:170-182, 1970

41. Reynolds EM: Neurotoxicity of carbamazepine. Adv Neurol 2:345-354, 1975

42. Flegel KM, Col CH: Inappropriate antidiuresis during carbamazepine treatment. Ann Intern Med 87:722-723, 1977

43. Ashton MG, Ball SG, Thomas TH, et al: Water intoxication associated with carbamazepine treatment. Br Med J 1:1134-1135, 1977

44. White MG, Fetner CD: Treatment of the syndrome of inappropriate secretion of antidiuretic hormone with lithium carbonate. N Engl J Med 292:390-392, 1975

45. Vieweg V, Glick JL, Herring S, et al: Absence of carbamazepine-induced hyponatremia among patients also given lithium. Am J Psych 144:943-947, 1987

46. Schatzberg AF: Evaluation and treatment of the refractory depressed patient, in Bernstein JG: Clinical Psychopharmacology, 2nd ed., Boston, John Wright-PSG Inc., pp. 77-92, 1984

47. Stern SL, Mendels J: Drug combinations in the treatment of refractory depression: a review. J Clin Psych 42:368-373, 1981

48. Feighner JP, Herbstein J, Damlouji N: Combined MAOI, TCA, and direct stimulant therapy of treatment-resistent depression. J Clin Psych 46:206-209, 1985

49. Flor-Henry P: Psychosis and temporal lobe epilepsy-a controlled investigation. Epilepsia 10:363-395, 1969

50. Perez MM, Trimble MR, Murray NMF et al: Epileptic psychosis: an evaluation of PSE profiles. Br J Psych 141:155-163, 1985

51. Post RM, Kopanda RT: Cocaine, kindling, and psychosis. Am J Psych 133:627-633, 1976

52. Wada JA: Pharmacological prophylaxis in the kindling model of epilepsy. Arch Neurol 34:389-395, 1977

53. Post RM, Berretini W, Uhde TW, et al: Selective response to the anticonvulsant carbamazepine in manic-depressive illness: a case study. J Clin Psychopharm 4:178185,1984 